\title{
Percutaneous Vertebroplasty Improves Pain Control and Quality of Life in Patients Suffering from Back Pain: A Single Center Experience
}

\author{
Daniele Maiettini, ${ }^{1,}$ Gianluigi Orgera, ${ }^{2}$ Michele Bisaccia, ${ }^{3}$ Luigi Piscitelli, ${ }^{3}$ Florindo Laurino,${ }^{2}$ Luigi \\ Meccariello, ${ }^{4}$ Stefania Rebonato, ${ }^{5}$ Elisabetta Schiaroli, ${ }^{6}$ Michele Rossi, ${ }^{2}$ and Alberto Rebonato ${ }^{1}$ \\ ${ }^{1}$ Department of Surgical and Biomedical Science, Radiology Unit, S.M. Misericordia Hospital, University of Perugia, Perugia, Italy \\ ${ }^{2}$ Department of Radiology, St. Andrea Hospital, University of Rome "La Sapienza", Rome, Italy \\ ${ }^{3}$ Department of Surgical and Biomedical Science, Orthopaedic Unit, S.M. Misericordia Hospital, University of Perugia, Perugia, Italy \\ ${ }^{4}$ Department of Medical and Surgical Sciences and Neuroscience, Section of Orthopedics and Traumatology, University of Siena, University Hospital "Santa Maria alle Scotte", \\ Siena, Italy \\ ${ }^{5}$ Department of Nuclear Medicine, Santa Maria Goretti Hospital, Latina, Italy \\ ${ }^{6}$ Department of Medicine, Infectious Diseases Unit, S.M. Misericordia Hospital, University of Perugia, Perugia, Italy \\ "Corresponding author: Daniele Maiettini, Department of Surgical and Biomedical Science, Radiology Unit, S.M. Misericordia Hospital, University of Perugia, Perugia 06132, \\ Italy. Tel: +39-3490907268, Fax: +39-0755784084, E-mail: danielemaiettini@gmail.com
}

Received 2016 August 25; Revised 2016 November 01; Accepted 2017 February 06.

\begin{abstract}
Background/Objectives: The purpose of this study was to assess the efficacy of pain control at a single center in a population of patients with osteoporotic fractures or vertebral metastasis after vertebroplasty (VP).

Patients and Methods: We retrospectively evaluated 163 patients who underwent VP at our institution between January 2008 and March 2016. Pain was measured with the visual analogue scale(VAS). The impact of pain on the quality of life (QoL) of the patients was estimated using the modified Roland-Morris questionnaire(RMQ). The VAS and RMQ values were calculated before the VP procedure and at one month and 6 months after the treatment.

Results: VAS and RMQ mean scores were 7.8, 3.9 and 3.5, and 20.7, 11.5 and 9.6 before the procedure and at the 1 month and 6 months follow-up, respectively, which showed significant improvement $(\mathrm{P}<0.0001)$. A significant correlation was noticed between the VAS scores and the RMQ values at the base line $(\mathrm{P}=0.008 ; \mathrm{r}=0.21)$.

Conclusion: This retrospective study assessed the efficacy of VP treatment for vertebral fractures due to osteoporosis or tumor infiltration and showed significant pain relief and improved QoL.
\end{abstract}

Keywords: Back Pain, Percutaneous Vertebroplasty, Pain, Percutaneous Vertebroplasty, Pain, Quality of Life

\section{Background}

Percutaneous vertebroplasty (PV) is a well-established treatment for stabilization of vertebral bodies in both vertebral fractures and vertebral metastasis (1). Osteoporosis is the most common cause of fractures occurring at different anatomical sites, and one of the most common is fracture of vertebral bodies $(2,3)$. Moreover, the most common site of bone metastases are the vertebrae, which is likely due to their high vascularization (4), and this is of particular clinical importance in the breast, lung, kidney, and prostate cancers (5-8).

Because of the prevalence of these diseases, vertebral body metastases (VBM) and vertebral fractures represent the most common etiologies of chronic pain (9). The utility and effectiveness of PV is most often evaluated on the basis of short-and long-term pain relief, and the quality of life (10).

Many different scores are used to evaluate patients' pain, vertebral disease related pain, and quality of life. One of the most common available score systems is the visual analogue scale, which is simple and easy to use, even if not designed specifically for back pain. A number of diseasespecific questionnaires have been developed to assess lowback pain (11-14).

\section{Objectives}

The purpose of this study was to assess the efficacy of pain control at a single center in a population of patients with osteoporotic fractures or vertebral metastasis who received vertebroplasty.

\section{Patients and Methods}

\subsection{Patients}

We retrospectively evaluated all patients who underwent vertebroplasty at our institution between January 2008 and March 2016. Institutional review board approval 
was obtained for the study, and a written informed consent was gathered from all patients.

We included patients who underwent vertebroplasty (VP) for 1) painful primary and secondary osteoporotic vertebral fractures refractory to conservative medical therapy and 2) painful vertebrae with extensive osteolysis or invasion secondary to a benign or malignant tumor (e.g., myeloma, hemangioma, or metastasis) (15).

The exclusion criteria were (1) involvement in more than two vertebral bodies, (2) cervical vertebrae involvement, (3) patients younger than 18 years or older than 85 years, and (4) performance of other procedures in addition to VP in the same session (e.g., thermoablations or nucleoplasty).

Absolute contraindications were (1) asymptomatic spine fractures, (2) presence of local or systemic infection, (3) retropulsed bone fragment resulting in myelopathy, (4) spinal canal compression due to tumor development resulting in myelopathy, (5) uncorrectable coagulopathy, and (6) allergy to the materials used in the vertebroplasty procedure (15).

Data on 231 patients who met the inclusion criteria were collected for this study. Seventy-one patients were excluded because they met the exclusion criteria: 17 had VP performed on three vertebrae, one had VP performed on four vertebrae, five patients underwent cervical VP, three were over 90 years old, and 43 underwent previous thermoablation.

Vertebral body fractures or osteolysis were detected using plain films or cross-sectional imaging, computed tomography (CT), or magnetic resonance imaging (MRI).

\subsection{Pre-procedure Imaging and Procedure Guidance}

All patients underwent a pre-procedure MRI or CT scan of the spine, including at least two vertebral bodies, one above and one below the suspected level of the fracture. CT reconstruction scans provided $1 \mathrm{~mm}$ axial, coronal and sagittal multiplanar reconstructions (MPRs). A pre-procedure CT or MRI was used to estimate the extent of vertebral compression and bone impairment, to detect retropulsed bone fragments or posterior wall interruptions, and to plan access to the vertebral body.

\subsection{Procedure and Follow-up}

Patient admission at the hospital was performed the day prior to the procedure. Patients' pain and disabilities were assessed using two scoring systems. Pain was estimated with the visual analogue scale (VAS), which provides a scale from 0 (no pain) to 10 (worst pain imagined). Pain related disability was measured using the modified Roland-Morris questionnaire (RMQ), Italian version (14), which provides 24 assessments related to back pain and daily activities (scale from 0 to 24 points; the latter represents the worst score).

All patients received prophylactic antibiotic therapy intravenously before the procedure (750 $\mathrm{mg}$ of cefuroxime). All procedures were performed using CT guidance under conscious sedation (general anesthesia was performed for patients who did not tolerate sedation). The operator decided on a personal preference to use fluoroscopic guidance with a portable C-arm in the CT suite. All procedures were conducted with the patient in the prone position. We used a posterior percutaneous approach at all levels (providing an extrapedicular or transpedicular approach above T10 and below T10, respectively).

In all cases, we used a 10-gauge vertebroplasty needle (Optimed, Ettlingen, Germany). A unipedicular or bipedicular access was performed on the basis of the operator's preference. A slow injection of 2-6 $\mathrm{ml}$ of polymethylmethacrylate(PMMA) was given (Osteopal 40 and Osteopal V, Biomet Deutschland GmbH, Berlin, Germany). The injection was gently and slowly performed using an Optimed Gangi Cemento-Re Gun (Optimed, Ettlingen, Germany) under intermittent CT fluoroscopy or fluoroscopy with gradual withdrawing of the needle. A CT scan was performed immediately after needle removal. Patients were kept on strict bed rest for 2 hours and discharged the same day of the procedure or the day after. VAS and Roland-Morris questionnaire (RMQ) values were calculated at one month and 6 months after the treatment on an outpatient basis or by phone.

\subsection{Statistics}

Descriptive statistics were calculated for all variables evaluated, reporting raw numbers, frequencies and averages. Student's t test was used to test for significant differences between continuous variables. A chi-squared test was used for discrete variables. Statistical analyses were performed using MedCalc Statistical Software version 14.8.1 (MedCalc Software bvba, Ostend, Belgium).

\section{Results}

A total of 163 patients were included in this study. The mean age was 71.5 years (SD 10.73; $\min 42$, max 89). Fifty-three patients were male and 107 female. Only thirty patients had painful vertebrae osteolysis or invasion secondary to a benign or malignant tumor. Forty-three patients underwent two VPs in the same session. A total of 203 VPs were performed: 1 on D5, 2 on D6, 5 on D7, 6 on D8, 6 on D9, 11 on D18, 18 on D11, 29 on D12, 38 on L1, 27 on L2, 23 on L3, 25 on L4, and 12 on L5. Patients with osteoporotic 
fractures had a higher mean age $(\mathrm{P}=0.003)$. The distribution of treated vertebrae was different considering osteoporotic or secondary to tumor fractures $(\mathrm{P}=0.04)$. No difference was found between patients who underwent one or two vertebrae treatments in the same session $(\mathrm{P}=0.06)$ or regarding $\operatorname{sex}(\mathrm{P}=0.27)$ between the two groups.

The VAS mean score was 7.8 (SD 1.2), 3.9 (SD 2.4), and 3.5 (SD 1.3) before the procedure and at 1 month and 6 months follow-up, respectively, showing a significant decrease $(\mathrm{P}<$ 0.0001) (Figure 1). The RMQ mean score was 20.7 (SD 3.2), 11.5 (SD 3.5), and 9.6 (SD 3.3) before the procedure and at 1 month and 6 months follow-up, respectively, showing a significant decrease $(\mathrm{P}<0.0001)$ (Figure 2$)$.

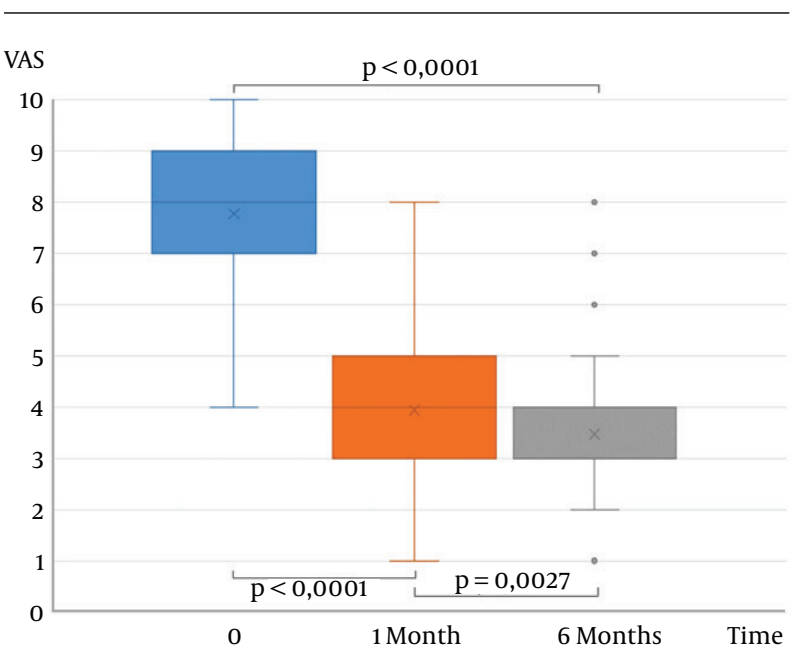

Figure 1. Mean overall visual analogue scale (VAS) score at the base line and at month and 6 months of follow-up Showing significant improvement (Student's t Test)

There was no difference in baseline VAS and RMQ scores, as well as at 1 month and 6 months follow-up, between patients with painful vertebrae secondary to benign or malignant tumors or osteoporotic vertebral compression fractures.

A significant correlation was noticed between the VAS scores and the RMQ scores at baseline $(\mathrm{P}=0.008 ; \mathrm{r}=0.21)$ (Figure 3), but this correlation was not more evident at the 1 month $(\mathrm{P}=0.62)$ and 6 months $(\mathrm{P}=0.63)$ follow-up.

\section{Discussion}

This retrospective study evaluated the efficacy of VP for treatment of vertebral fractures due to osteoporosis or tumor infiltration showing a clinically significant pain relief and an improved quality of life.

To date, there have been many reports on VP for spinal fracture treatment associated with both tumor invasion

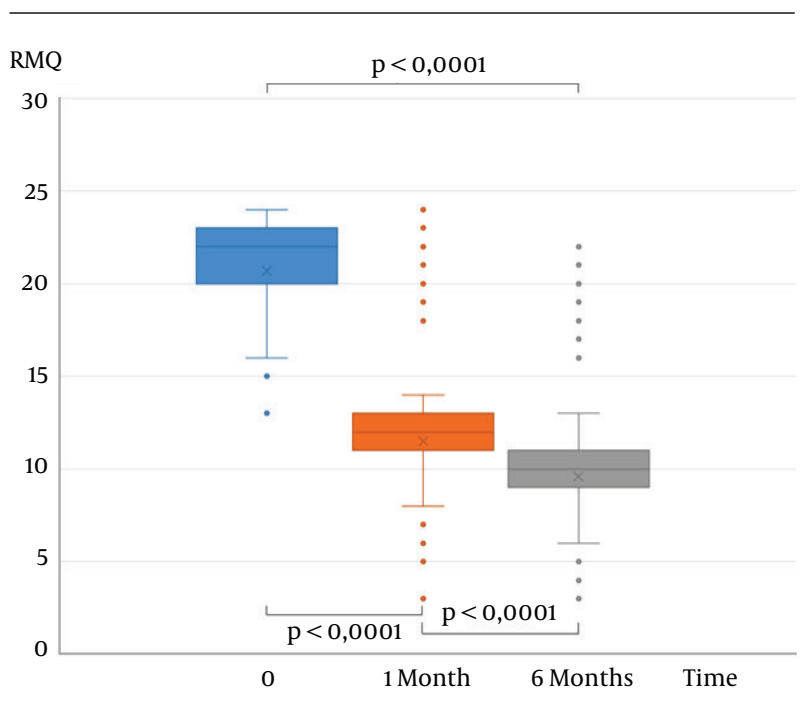

Figure 2. Mean overall roland-morris questionnaire (RMQ) score at the base line and at 1 month and 6 months of follow-up showing significant improvement (Student's t Test)

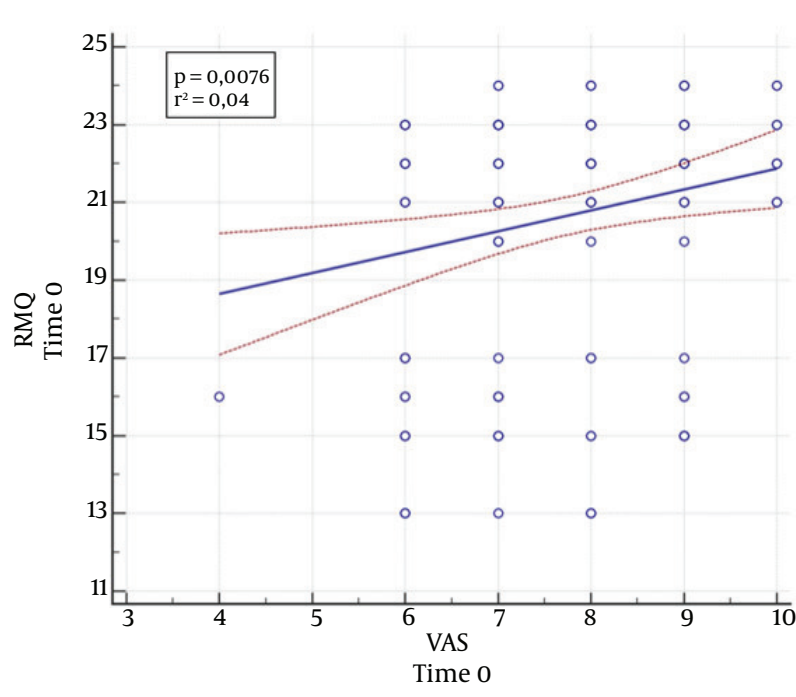

Figure 3. Significant correlation between visual analogue scale (VAS) and rolandmorris questionnaire (RMQ) scores at base line (Time 0 )

and osteoporosis. Most of these reports demonstrated the efficacy of VP in reducing pain, aiding mobility and responding to physiotherapy, as well as improving the quality of life $(16,17)$.

Nevertheless, the level of evidence reached by this study is still not well established because some randomized clinical trials (RCTs) on the topic of percutaneous vertebral augmentation showed a trend of improvement in the short-term outcome compared with nonsurgical management and a placebo-simulated procedure $(18,19)$. 
Yang et al. in their prospective RCT concerning patients older than 70 years demonstrated that early VP allows faster and better pain relief and improved functional outcomes, which lasted for 1 year and was accompanied by fewer complications than conservative treatment (20). In contrast, Macias-Hernandez et al. concluded that percutaneous VP had no advantages over conservative treatment for pain and function in a group of women $\geq 60$ years of age with osteoporosis (21). Moreover, Clarençonet et al. recently suggested that VP remains a safe and effective technique for pain relief, independent of the underlying disease in patients $\geq 80$ years of age (22).

In our series, VP seemed to be effective in the treatment of osteoporotic fractures with a significant improvement in pain and quality of life. Even in the case of neoplastic invasion, VP showed significant efficacy. The relief of pain was shown to be prompt, with good results already at 4 weeks after the procedure, with a slight further improvement at 6 months.

In cases of neoplastic invasion, many authors have proposed to precede the VP with thermal-ablation to have better control of the disease. These approaches showed promising results and appeared to be safe and effective in the treatment of painful neoplastic lesions (23). Nevertheless, the best effectiveness of this technique needs to be clearly demonstrated (24).

The present study validated the RMQ in both osteoporotic and neoplastic fractures, showing a strong correlation with VAS scores (14) at the baseline, while the absence of a correlation during the follow-up was probably due to the small gap between values since there was significant improvement from the baseline.

This study was limited by many factors. The retrospective nature of our study did not allow us to include an optimal control group, particularly comparing VP to medical treatment. The population was enrolled from a single center within a long time with the consequent possibility of an inhomogeneous approach. There is increasing evidence that optimizing patient outcomes results in improved quality of life and that pain management is an essential part of comprehensive management of oncologic and elderly patients.

Our study suggested that VP is a safe technique showing similar clinical effectiveness in terms of pain relief and quality of life independently of vertebral fracture etiology; however, these results need to be confirmed by prospective randomized controlled studies.

\section{Acknowledgments}

None.

\section{Footnotes}

Authors' Contributions: Study concept and design: Rebonato A, Maiettini, Rossi; acquisition of data: Laurino, Orgera, and Piscitelli; analysis and interpretation of data: Maiettini, and Meccariello; drafting of the manuscript: Reboanto S, Schiaroli, and Piscitelli; critical revision of the manuscript for important intellectual content: Rebonato A, Rossi, Orgera, and Bisaccia; statistical analysis: Maiettini, Meccariello, and Piscitelli; study supervision: Rebonato A, Rossi, and Bisaccia

Financial Disclosure: All authors disclose that they do not have any financial and personal relationships with other people or organizations that could inappropriately influence (bias) their work. Examples of potential conflicts of interest include employment, consultancies, stock ownership, honoraria, paid expert testimony, patent applications/registrations, and grants or other funding

Funding/Support: None declared.

\section{References}

1. Mattie R, Laimi K, Yu S, Saltychev M. Comparing Percutaneous Vertebroplasty and Conservative Therapy for Treating Osteoporotic Compression Fractures in the Thoracic and Lumbar Spine: A Systematic Review and Meta-Analysis. J Bone Joint Surg Am. 2016;98(12):1041-51. doi: 10.2106/JBJS.15.00425. [PubMed: 27307365].

2. Haleem S, Lutchman L, Mayahi R, Grice JE, Parker MJ. Mortality following hip fracture: trends and geographical variations over the last 40 years. Injury. 2008;39(10):1157-63. doi:10.1016/j.injury.2008.03.022. [PubMed: 18653186].

3. Lau E, Ong K, Kurtz S, Schmier J, Edidin A. Mortality following the diagnosis of a vertebral compression fracture in the Medicare population. J Bone Joint Surg Am. 2008;90(7):1479-86. doi: 10.2106/JBJS.G.00675. [PubMed: 18594096].

4. Boland PJ, Lane JM, Sundaresan N. Metastatic disease of the spine. Clin Orthop Relat Res. 1982(169):95-102. doi:10.1097/00003086-19820900000012. [PubMed: 7105592].

5. Coleman RE. Bisphosphonates: clinical experience. Oncologist. 2004;9 Suppl 4:14-27. doi: 10.1634/theoncologist.9-90004-14. [PubMed: 15459426].

6. Rebonato A, Vannini E, Giganti M, Volterrani L, Fonio P, Piscioli I, et al. [Small renal oncocytoma $(</=4 \mathrm{~cm})$ : enhancement patterns on triphasic spiral computed tomography]. Recenti Prog Med. 2012;103(11):477-82. doi: 10.1701/1166.12892. [PubMed: 23096735].

7. Coleman RE. Clinical features of metastatic bone disease and risk of skeletal morbidity. Clin Cancer Res. 2006;12(20 Pt 2):6243s-9s. doi: 10.1158/1078-0432.CCR-06-0931. [PubMed: 17062708].

8. Rebonato A, Pierotti L, Barberini F, Rosi G, Macarini L, Scialpi M. [Small renal cell carcinoma $(</=4 \mathrm{~cm})$ : enhancement patterns on triphasic spiral CT]. Recenti Prog Med. 2012;103(11):471-6. doi: 10.1701/1166.12891. [PubMed: 23096734].

9. Loblaw DA, Perry J, Chambers A, Laperriere NJ. Systematic review of the diagnosis and management of malignant extradural spinal cord compression: the Cancer Care Ontario Practice Guidelines Initiative's Neuro-Oncology Disease Site Group. J Clin Oncol. 2005;23(9):2028-37. doi:10.1200/JCO.2005.00.067. [PubMed: 15774794].

10. Widmer Soyka RP, Helgason B, Hazrati Marangalou J, van den Bergh JP, van Rietbergen B, Ferguson SJ. The Effectiveness of Percutaneous 
Vertebroplasty Is Determined by the Patient-Specific Bone Condition and the Treatment Strategy. PLoS One. 2016;11(4):e0151680. doi: 10.1371/journal.pone.0151680. [PubMed: 27100630].

11. Monticone M, Ambrosini E, Rocca B, Nava T, Terragni E, Cerri C, et al Development of the Italian Version of the Pain Vigilance and Awareness Questionnaire in Subjects with Chronic Low Back Pain: Crosscultural Adaptation, Confirmatory Factor Analysis, Reliability and Validity. Int JBehav Med. 2016;23(2):214-23. doi: 10.1007/s12529-015-9507-x. [PubMed: 26362465].

12. Johnson L. Outcomes analysis in spinal research. How clinical research differs from outcomes analysis. Orthop Clin North Am. 1994;25(2):205-13. [PubMed: 8159395].

13. Roland M, Morris R. A study of the natural history of back pain. Part I: development of a reliable and sensitive measure of disability in lowback pain. Spine (Phila Pa 1976). 1983;8(2):141-4. doi: 10.1097/00007632198303000-00005. [PubMed: 6222486].

14. Padua R, Padua L, Ceccarelli E, Romanini E, Zanoli G, Bondi R, et al. Italian version of the Roland Disability Questionnaire, specific for low back pain: cross-cultural adaptation and validation. Eur Spine J. 2002;11(2):126-9. doi: 10.1007/s005860100262. [PubMed: 11956918].

15. McGraw JK, Cardella J, Barr JD, Mathis JM, Sanchez O, Schwartzberg MS, et al. Society of Interventional Radiology quality improvement guidelines for percutaneous vertebroplasty. J Vasc Interv Radiol. 2003;14(9 Pt 2):S311-5. doi: 10.1097/01.RVI.0000082822.75926.4C. [PubMed: 14514838]

16. Evans AJ, Jensen ME, Kip KE, DeNardo AJ, Lawler GJ, Negin GA, et al. Vertebral compression fractures: pain reduction and improvement in functional mobility after percutaneous polymethylmethacrylate vertebroplasty retrospective report of 245 cases. Radiology. 2003;226(2):366-72. doi: 10.1148/radiol.2262010906. [PubMed 12563127].

17. Barragan-Campos HM, Vallee JN, Lo D, Cormier E, Jean B, Rose M, et al. Percutaneous vertebroplasty for spinal metastases: complications. Radiology. 2006;238(1):354-62. doi: 10.1148/radiol.2381040841. [PubMed: 16373777].
18. Wardlaw D, Cummings SR, Van Meirhaeghe J, Bastian L, Tillman JB, Ranstam J, et al. Efficacy and safety of balloon kyphoplasty compared with non-surgical care for vertebral compression fracture (FREE): a randomised controlled trial. Lancet. 2009;373(9668):1016-24. doi: 10.1016/s0140-6736(09)60010-6.

19. Kallmes DF, Comstock BA, Gray LA, Heagerty PJ, Hollingworth W, Turner JA, et al. Baseline pain and disability in the Investigational Vertebroplasty Efficacy and Safety Trial. AJNR Am J Neuroradiol. 2009;30(6):1203-5. doi:10.3174/ajnr.A1519. [PubMed:19246522].

20. Yang EZ, Xu JG, Huang GZ, Xiao WZ, Liu XK, Zeng BF, et al. Percutaneous Vertebroplasty Versus Conservative Treatment in Aged Patients With Acute Osteoporotic Vertebral Compression Fractures: A Prospective Randomized Controlled Clinical Study. Spine (Phila Pa 1976). 2016;41(8):653-60. doi: 10.1097/BRS.0000000000001298. [PubMed: 26630417].

21. Macias-Hernandez SI, Chavez-Arias DD, Miranda-Duarte A, CoronadoZarco R, Diez-Garcia MP. Percutaneous Vertebroplasty Versus Conservative Treatment and Rehabilitation in Women with Vertebral Fractures due to Osteoporosis: A Prospective Comparative Study. Rev Invest Clin. 2015;67(2):98-103. [PubMed: 25938842].

22. Clarencon F, Fahed R, Gabrieli J, Guermazi Y, Cormier E, MoletBenhamou L, et al. Safety and Clinical Effectiveness of Percutaneous Vertebroplasty in the Elderly ( $>\mid=80$ years). Eur $R a$ diol. 2016;26(7):2352-8. doi: 10.1007/s00330-015-4035-2. [PubMed: 26427699].

23. Munk PL, Rashid F, Heran MK, Papirny M, Liu DM, Malfair D, et al. Combined cementoplasty and radiofrequency ablation in the treatment of painful neoplastic lesions of bone. J Vasc Interv Radiol. 2009;20(7):903-11. doi:10.1016/j.jvir.2009.03.035. [PubMed:19481469].

24. Orgera G, Krokidis M, Matteoli M, Varano GM, La Verde G, David V, et al Percutaneous vertebroplasty for pain management in patients with multiple myeloma: is radiofrequency ablation necessary? Cardiovasc Intervent Radiol. 2014;37(1):203-10. doi: 10.1007/s00270-013-06240. [PubMed: 23652417]. 